\title{
Sprouty 2 inhibits amphiregulin-induced down-regulation of E-cadherin and cell invasion in human ovarian cancer cells
}

\author{
Jung-Chien Cheng ${ }^{1, *}$, Hsun-Ming Chang ${ }^{1, *}$, Siyuan Xiong ${ }^{1}$, Wai-Kin So ${ }^{1}$, Peter C. K. \\ Leung ${ }^{1}$ \\ ${ }^{1}$ Department of Obstetrics and Gynaecology, Child \& Family Research Institute, University of British Columbia, Vancouver, \\ British Columbia, Canada V5Z 4H4 \\ *These authors have contributed equally to this work \\ Correspondence to: Peter C.K. Leung, email: peter.leung@ubc.ca
}

Keywords: amphiregulin, E-cadherin, ovarian cancer, sprouty2

Received: August 12, $2016 \quad$ Accepted: October 22, 2016

Published: November 07, 2016

\section{ABSTRACT}

Similar to Drosophila Sprouty (SPRY), mammalian SPRY proteins inhibit the receptor tyrosine kinase-mediated activation of cellular signaling pathways. SPRY2 expression levels have been shown to be down-regulated in human ovarian cancer, and patients with low SPRY 2 expression have significantly poorer survival than those with high SPRY2 expression. In addition, epidermal growth factor receptor (EGFR) is overexpressed in human ovarian cancer and is associated with more aggressive clinical behavior and a poor prognosis. Amphiregulin (AREG), the most abundant EGFR ligand in ovarian cancer, binds exclusively to EGFR and stimulates ovarian cancer cell invasion by down-regulating E-cadherin expression. However, thus far, the roles of SPRY2 in AREG-regulated E-cadherin expression and cell invasion remain unclear. In the present study, we show that treatment with AREG up-regulated SPRY 2 expression by activating the EGFR-mediated ERK1/ 2 signaling pathway in two human ovarian cancer cell lines, SKOV3 and OVCAR5. In addition, overexpression of SPRY2 attenuated the AREG-induced down-regulation of E-cadherin by inhibiting the induction of the E-cadherin transcriptional repressor, Snail. Moreover, SPRY2 overexpression attenuated AREG-stimulated cell invasion and proliferation. This study reveals that SPRY2 acts as a tumor suppressor in human ovarian cancer and illustrates the underlying mechanisms that can be used as possible targets for the development of novel therapeutics.

\section{INTRODUCTION}

Ovarian cancer is the fifth most common cause of cancer death in women due to the lack of effective screening methods, a paucity of symptoms during the early stages of the disease, and limited responses to treatment in the late stages of disease. Many studies have demonstrated that epidermal growth factor receptor (EGFR) is overexpressed in human ovarian cancer, and EGFR overexpression is associated with more aggressive clinical behavior and a poor prognosis [1,2]. Although multiple ligands can bind to and activate EGFR, only epidermal growth factor (EGF), amphiregulin (AREG) and transforming growth factor- $\alpha$ (TGF- $\alpha$ ) bind exclusively to EGFR [3,4]. AREG exerts its biological functions by activating EGFR in an autocrine and/or paracrine fashion $[5,6]$. A recent study demonstrates that AREG is the most abundant EGFR ligand in ascites fluid collected from patients with ovarian cancer and in conditioned media from ovarian cancer cells [7]. In addition, treatment with a neutralizing monoclonal anti-AREG antibody inhibits the growth of ovarian cancer xenografts and enhances chemotherapy efficacy [7]. Taken together, these results indicate that AREG plays important roles in regulating ovarian tumorigenesis.

The majority of women with ovarian cancer are diagnosed at a late stage, when the cancer has spread beyond the confines of the ovary. E-cadherin is a transmembrane glycoprotein localized on the surface of epithelial cells in regions of cell-cell contact, known 
as adherens junctions. E-cadherin mediates calciumdependent cell-cell adhesion, which is important for maintaining cell polarity and normal epithelial architecture [8]. Loss of E-cadherin expression is the hallmark of the epithelial-mesenchymal transition, which has been shown to play important roles in regulating metastasis and tumor progression [9]. Ovarian cancer cells with low E-cadherin levels are more invasive, and loss of E-cadherin expression in tumors is associated with poor survival $[10,11]$. Our previous studies have demonstrated that activation of EGFR by different ligands contributes to the downregulation of E-cadherin and increases the migration and invasion of human ovarian cancer cells [12-20].

Sprouty (SPRY) protein was first identified in Drosophila as an antagonist of fibroblast growth factor (FGF) in tracheal development [21]. Thus far, four SPRY genes (SPRY1-4) with sequence similarity to Drosophila $S P R Y$ have been identified in mammals [22]. Similar to Drosophila SPRY, mammalian SPRY inhibits the activation of ERK1/2 signaling by various growth factors [23]. SPRY is aberrantly expressed in different types of human cancer and is involved in tumorigenesis [24]. Our previous study and others' studies have shown that SPRY2 expression is down-regulated in human ovarian cancer and that patients with low SPRY2 expression have significantly poorer survival than those with high SPRY2 expression [25-28]. These results suggest that SPRY2 acts as a tumor suppressor in ovarian cancer progression. However, the mechanisms involved in SPRY2-mediated tumor suppression remain unknown and require further investigation.

Despite the importance of AREG and EGFR in ovarian tumorigenesis, whether SPRY2 is regulated by AREG and whether SPRY2 is involved in ovarian cancer progression are still unknown. The current study showed that treatment with AREG up-regulated SPRY2 expression in two human ovarian cancer cell lines, SKOV3 and OVCAR5. The stimulatory effect of AREG on SPRY2 expression was completely blocked by pre-treatment with an EGFR inhibitor, AG1478, and by siRNA-mediated EGFR knockdown. In addition, the effect of AREG on SPRY2 expression was abolished by inhibiting activation of the ERK1/2, but not the PI3K/AKT, signaling pathway. Moreover, we showed that overexpression of SPRY2 attenuated the AREG-induced down-regulation of E-cadherin, cell invasion and proliferation.

\section{RESULTS}

\section{High AREG mRNA levels are associated with reduced disease-free survival in patients with ovarian cancer}

To investigate AREG expression and its relationship with ovarian cancer patient survival, we queried mRNA expression data on 489 high-grade serous ovarian carcinomas samples that were published by the Cancer Genome Atlas (TCGA) Research Network [29]. Using cBioPortal for Cancer Genomics [30], our analyses showed up-regulation of AREG mRNA in 24 (5\%) of 489 cases (Figure 1A). No down-regulation of AREG mRNA was detected. Kaplan-Meier analyses showed that up-regulation of AREG mRNA was not significantly associated with overall survival (Logrank $P=0.193$ ) (Figure 1B). However, patients with up-regulated AREG mRNA had a significantly worse disease-free survival (Log-rank $P=0.0182$ ) (Figure 1C). These results, together with the findings of a recent study, indicate that AREG contributes to tumor progression and poor survival in human ovarian cancer [7].

\section{AREG up-regulates SPRY2 by activating EGFR in human ovarian cancer cells}

To examine the effect of AREG, two human ovarian cancer cell lines (SKOV3 and OVCAR5) that express AREG and EGFR were used as in vitro models [7, 19]. AREG protein levels can reach $100 \mathrm{ng} / \mathrm{mL}$ in normal human follicular fluid [31]. Therefore, we first treated SKOV3 cells with $100 \mathrm{ng} / \mathrm{mL}$ AREG for various periods of time. As shown in Figure 2A, 1 h treatment with AREG significantly up-regulated SPRY2 mRNA levels. The maximal effect was observed after $3 \mathrm{~h}$ of AREG treatment, and the induced AREG mRNA levels declined after $6 \mathrm{~h}$ of AREG treatment. We also examined the effect of different concentrations of AREG on SPRY2 expression. RT-qPCR results showed that treatment with $1 \mathrm{ng} / \mathrm{mL}$ AREG did not affect the mRNA levels of SPRY2 in SKOV3 cells, whereas treatment with 10 or $100 \mathrm{ng} / \mathrm{mL}$ AREG similarly and significantly up-regulated SPRY2 mRNA levels (Figure 2B). Western blot results showed similar effects: treatment with AREG transiently up-regulated SPRY2 protein levels in a dose-dependent manner (Figure 2C and 2D). Therefore, we used $10 \mathrm{ng} / \mathrm{mL}$ AREG for the following experiments.

To confirm the requirement of EGFR in AREGinduced up-regulation SPRY2 expression, SKOV3 cells were pre-treated with an EGFR inhibitor, AG1478, to block the activation of EGFR. As shown in Figure 3A and 3B, pre-treatment with AG1478 completed blocked the stimulatory effects of AREG on SPRY 2 mRNA and protein levels. To avoid off-target effects of the pharmacological inhibitor and further confirm that EGFR is required for AREG-induced SPRY2 expression, an siRNA-mediated knockdown approach was used to down-regulate endogenous EGFR expression. As shown in Figure 3C and 3D, EGFR siRNA significantly down-regulated EGFR mRNA and protein levels. In addition, the AREG-induced up-regulations of SPRY2 mRNA and protein levels 
were abolished by EGFR knockdown. AREG treatment similarly up-regulated SPRY2 expression in another human ovarian cancer cell line, OVCAR5 (Figure 4A). The stimulatory effect of AREG on SPRY2 expression in OVCAR5 cells was also abolished by inhibiting EGFR activity or expression (Figure 4B and 4C).
ERK1/2, but not PI3K/AKT, signaling is involved in AREG-induced SPRY2 up-regulation

We have previously shown that AREG can activate the ERK1/2 and PI3K/AKT signaling pathways in human ovarian cancer cells [13]. Therefore, we next examined

\section{A Altered in 24 (5\%) of 489 Ovarian Serous Cystadenocarcinoma}

AREG $\quad 5 \%$

\section{Genetic Alteration}

mRNA Upregulation

B
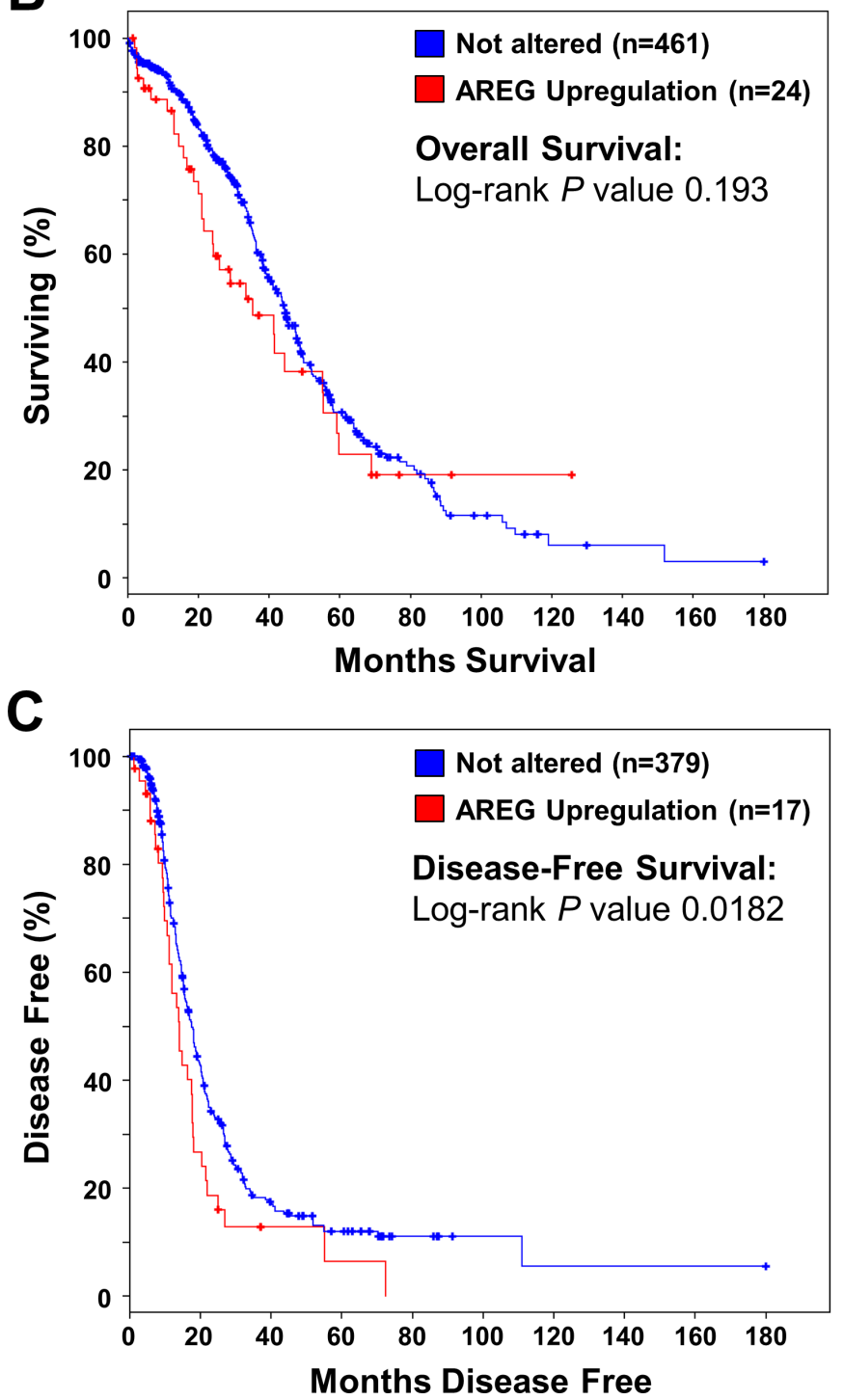

Figure 1: Up-regulation of AREG mRNA is associated with reduced disease-free survival in patients with high-grade serous ovarian carcinoma. The cBioPortal for Cancer Genomics was used to query high-grade serous ovarian carcinomas from The Cancer Genome Atlas ( $\mathrm{n}=489)$ for up-regulation of AREG mRNA above the median. A. OncoPrint results of cases with elevated AREG mRNA across all 489 high-grade serous ovarian carcinomas. B and C. Overall (B) and disease-free (C) survival differences between samples without and with elevated AREG mRNA levels were displayed as Kaplan-Meier survival curves with the associated $P$ value (Logrank test). 
whether activation of the ERK1/2 or PI3K/AKT signaling pathway is required for SPRY2 up-regulation induced by AREG. RT-qPCR and Western blot results showed that pre-treatment with a MEK inhibitor, U0126, not only decreased basal SPRY2 mRNA and protein expression but also abolished the AREG-induced up-regulation of SPRY 2 mRNA and protein levels in SKOV3 cells. Pretreatment with a PI3K inhibitor, LY294002, did not affect basal or AREG-up-regulated SPRY2 expression (Figure $5 \mathrm{~A}$ and $5 \mathrm{~B}$ ). To further confirm the involvement of ERK1/2 signaling in AREG-induced SPRY2 expression, ERK1/2 siRNAs were used to knockdown endogenous
ERK1/2 expressions. As shown in Figure 5C, knockdown of ERK1/2 abolished the stimulatory effect of AREG on SPRY2 expression in SKOV3 cells. Similar results were observed in OVCAR5 cells (Figure 5D).

\section{Overexpression of SPRY2 attenuates AREG- induced down-regulation of E-cadherin expression}

Our previous studies have shown that AREG induces human ovarian cancer cell invasion by downregulating E-cadherin expression [13, 14]. Since SPRY2
A

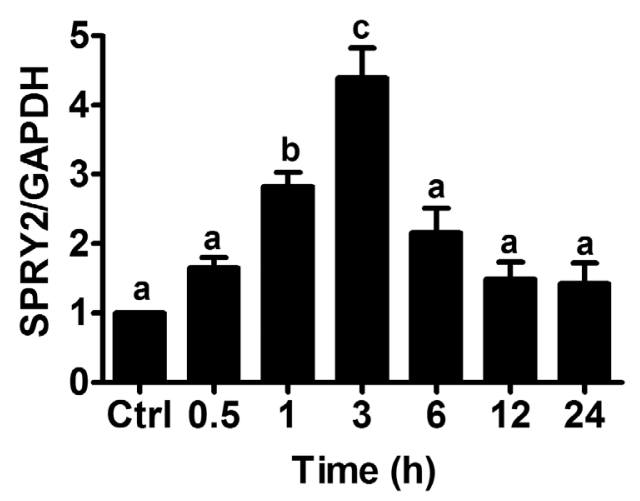

C

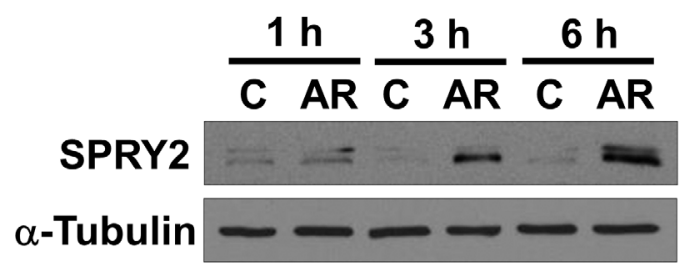

B

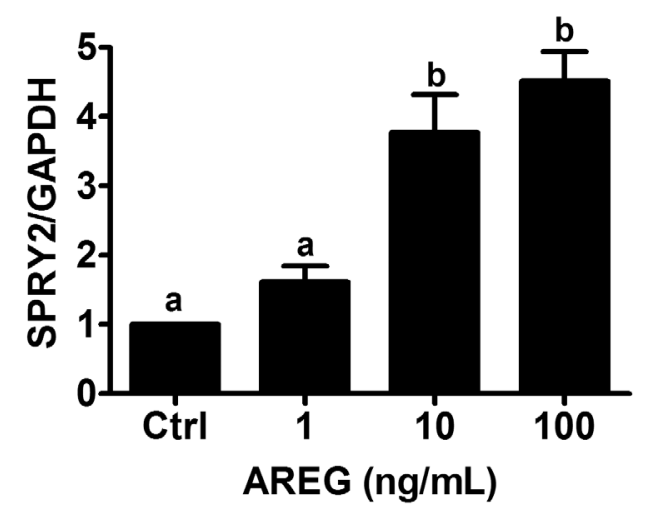

D

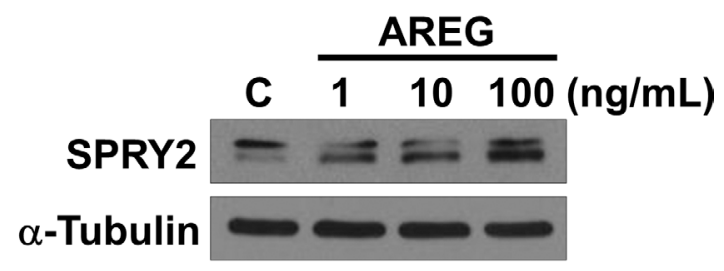

Figure 2: AREG up-regulates SPRY2 expression in human ovarian cancer cells. A. SKOV3 cells were treated with 100 $\mathrm{ng} / \mathrm{mL}$ AREG for different time periods, and SPRY2 mRNA levels were examined by RT-qPCR. SPRY2 mRNA level at each time point was normalized to GAPDH mRNA level at the same time point. B. SKOV3 cells were treated for $3 \mathrm{~h}$ with vehicle control or different concentrations of AREG, and SPRY2 mRNA levels were examined by RT-qPCR. C. SKOV3 cells were treated with $100 \mathrm{ng} / \mathrm{mL}$ AREG (AR) for different time periods, and SPRY2 protein levels were examined by Western blot. D. SKOV3 cells were treated for $3 \mathrm{~h}$ with vehicle control or different concentrations of AREG, and SPRY2 protein levels were examined by Western blot. The results are presented as the mean \pm SEM of at least three independent experiments. Values without a common letter are significantly different $(P<0.05)$. 
expression is down-regulated in human ovarian cancer, we examined whether AREG-induced E-cadherin downregulation can be attenuated by overexpressing SPRY2. As shown in Figure 6A and 6B, SKOV3 cells transfected with a vector encoding human SPRY2 expressed more SPRY2, whereas cells transfected with an empty vector did not

A

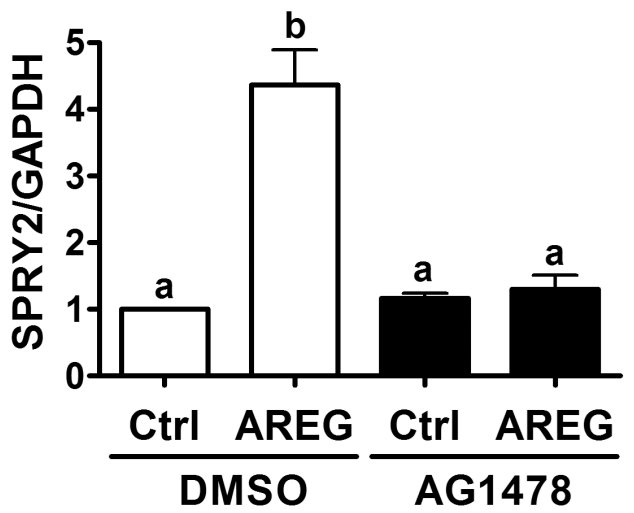

C
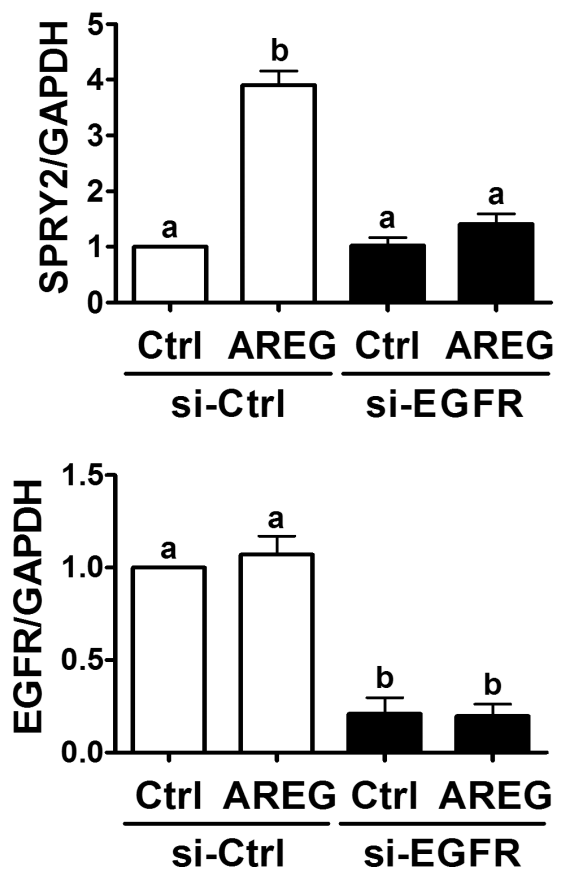

show an up-regulation of SPRY2. Importantly, SPRY2 overexpression attenuated the AREG-induced downregulation of E-cadherin mRNA and protein expression. Similarly, the inhibitory effect of AREG on E-cadherin expression was attenuated by SPRY2 overexpression in OVCAR5 cells (Figure 6C).
B
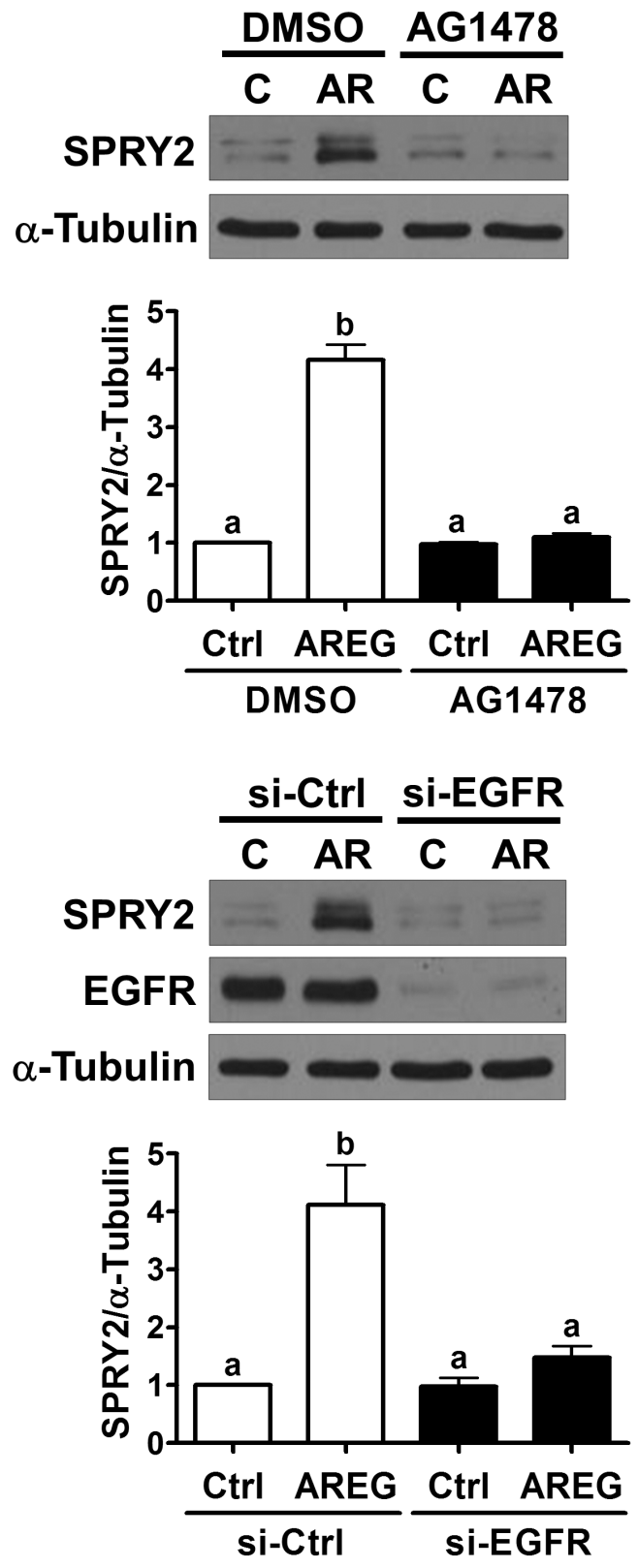

Figure 3: EGFR is required for the AREG-induced up-regulation of SPRY2 expression. A and B. SKOV3 cells were pretreated with vehicle control (DMSO) or $10 \mu \mathrm{M}$ AG1478 for $1 \mathrm{~h}$ and then treated with vehicle control (Ctrl) or $10 \mathrm{ng} / \mathrm{mL}$ AREG (AR) for $3 \mathrm{~h}$. The mRNA (A) and protein (B) levels of SPRY2 were examined by RT-qPCR and Western blot, respectively. C and D. SKOV3 cells were transfected with $50 \mathrm{nM}$ control siRNA (si-Ctrl) or EGFR siRNA (si-EGFR) for $48 \mathrm{~h}$ and then treated with vehicle control (Ctrl) or $10 \mathrm{ng} / \mathrm{mL}$ AREG (AR) for $3 \mathrm{~h}$. The mRNA (A) and protein (B) levels of SPRY2 and EGFR were examined by RT-qPCR and Western blot, respectively. The results are presented as the mean \pm SEM of at least three independent experiments. Values without a common letter are significantly different $(P<0.05)$. 


\section{Overexpression of SPRY2 attenuates AREG- induced Snail expression}

It has been well characterized that E-cadherin can be down-regulated by increasing the expression of its transcriptional repressors, Snail and Slug [32]. Therefore,

A

OVCAR5

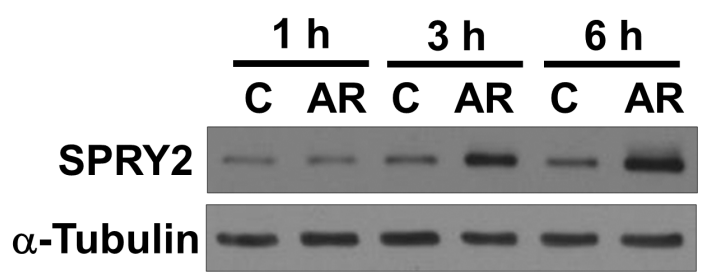

C

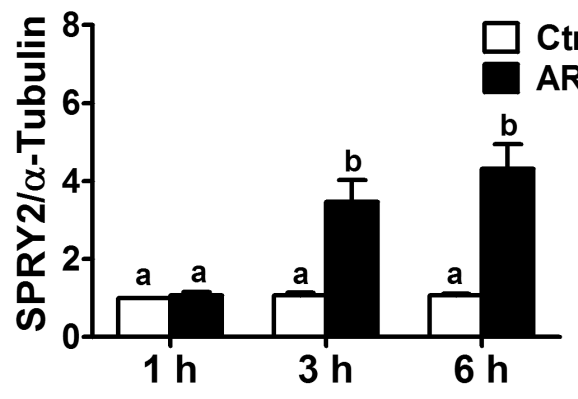

OVCAR5

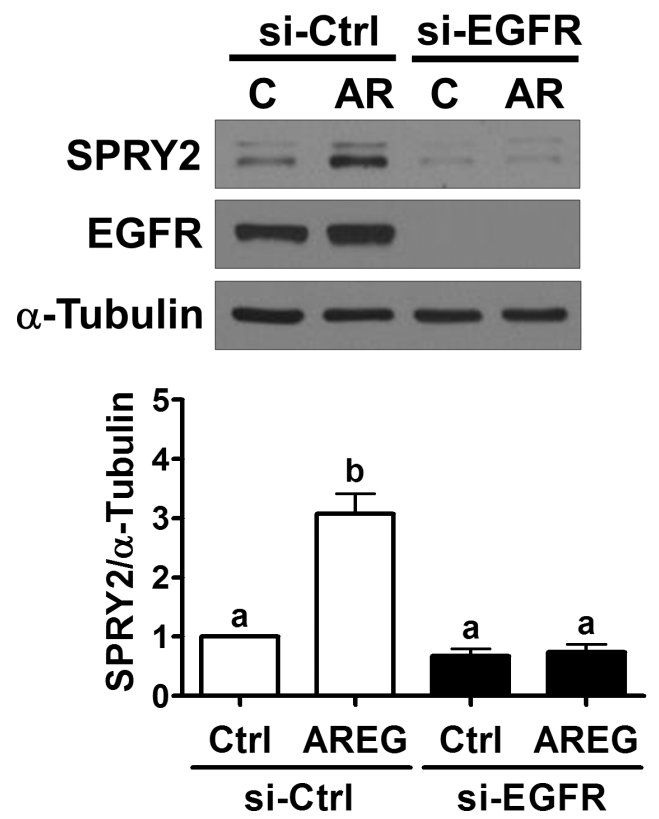

we examined whether SPRY2 overexpression affects the AREG-induced up-regulation of Snail and Slug. As shown in Figure 7A and 7B, AREG-treated SKOV3 cells showed increased Snail and Slug mRNA and protein levels. Interestingly, SPRY2 overexpression attenuated the AREG-induced up-regulation of Snail mRNA and protein

B

\section{OVCAR5}
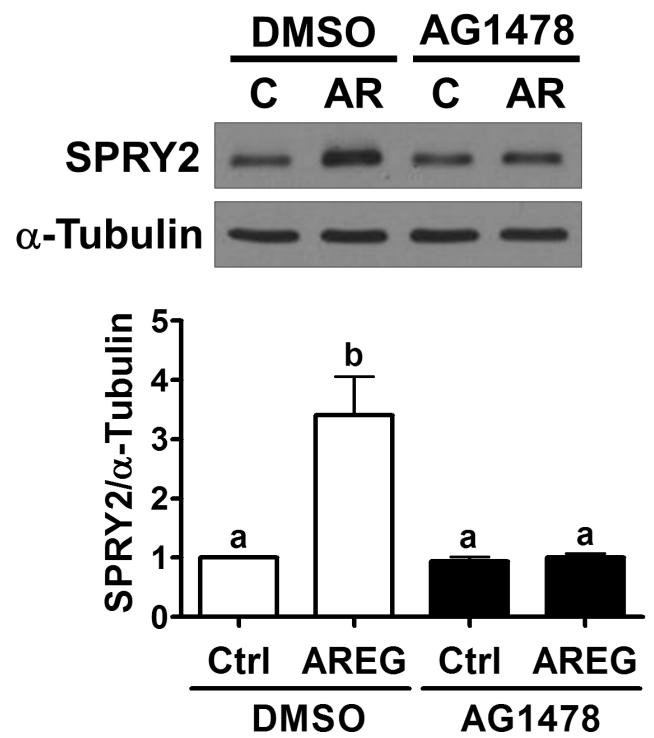

Figure 4: AREG up-regulates SPRY2 expression through EGFR in another human ovarian cancer cell line. A. OVCAR5 cells were treated with $10 \mathrm{ng} / \mathrm{mL}$ AREG (AR) for different time periods, and SPRY2 protein levels were examined by Western blot. B. OVCAR5 cells were pre-treated with vehicle control (DMSO) or $10 \mu \mathrm{M}$ AG1478 for $1 \mathrm{~h}$ and then treated with vehicle control (Ctrl) or $10 \mathrm{ng} / \mathrm{mL}$ AREG (AR) for $3 \mathrm{~h}$. SPRY2 protein levels were examined by Western blot. C. OVCAR5 cells were transfected with $50 \mathrm{nM}$ control siRNA (si-Ctrl) or EGFR siRNA (si-EGFR) for $48 \mathrm{~h}$ and then treated with vehicle control (Ctrl) or $10 \mathrm{ng} / \mathrm{mL}$ AREG (AR) for 3 $\mathrm{h}$. The protein levels of SPRY2 and EGFR were examined by Western blot. The results are presented as the mean \pm SEM of at least three independent experiments. Values without a common letter are significantly different $(P<0.05)$. 
levels without affecting basal Snail expression. However, SPRY2 overexpression did not affect the stimulatory effect of AREG on Slug expression. In OVCAR5 cells, overexpression of SPRY2 similarly attenuated the AREGinduced up-regulation of Snail, but not Slug, expression (Figure 7C).
Overexpression of SPRY2 attenuates AREGinduced cell invasion and proliferation

Given that overexpression of SPRY2 attenuated the AREG-induced down-regulation of E-cadherin in SKOV3 and OVCAR5 cells, we next examined
A

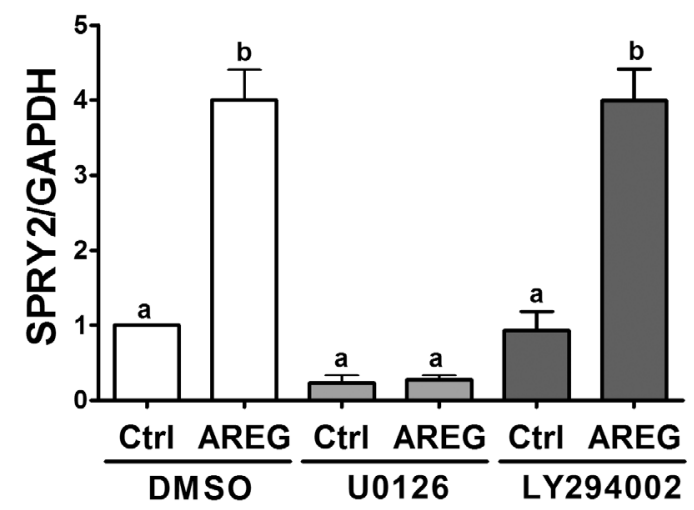

C
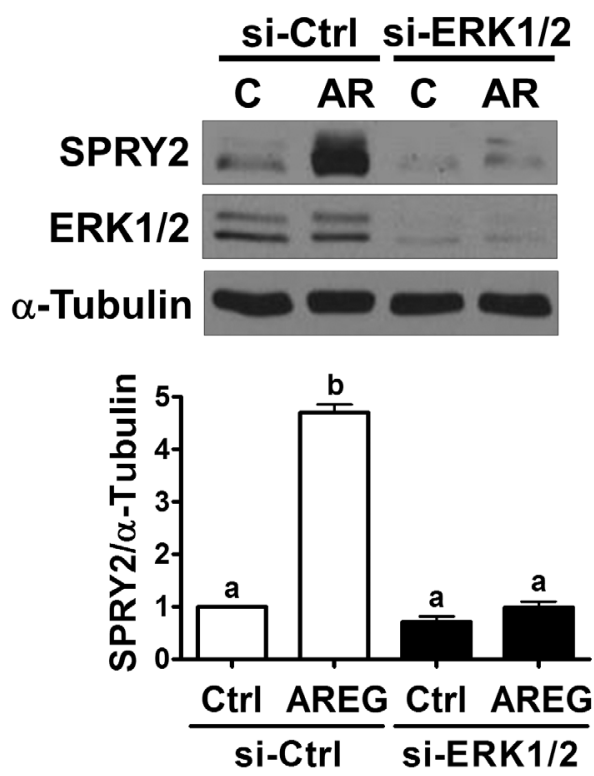

B

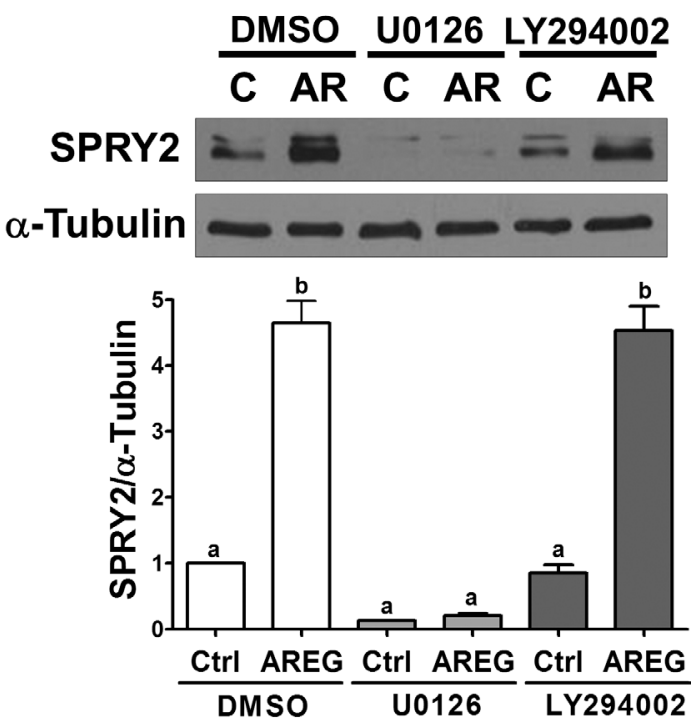

D

\section{OVCAR5}
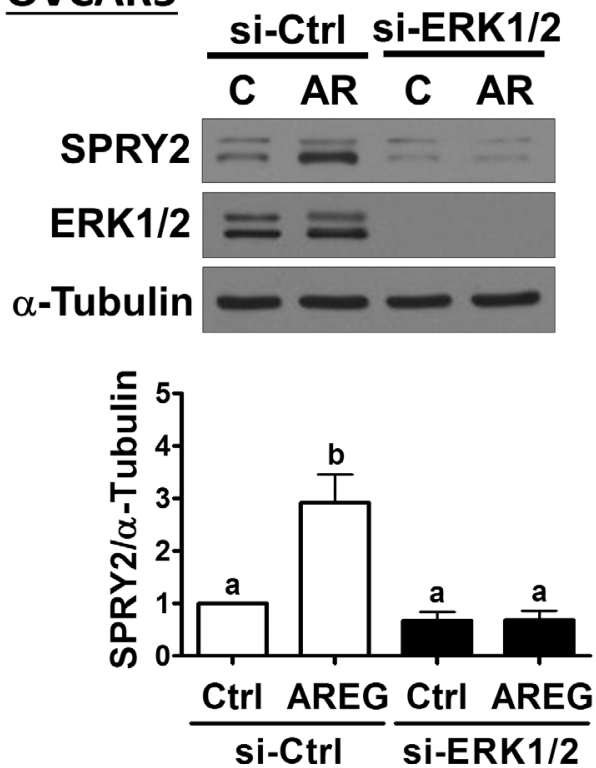

Figure 5: ERK1/2 is required for the AREG-induced up-regulation of SPRY2. A and B. SKOV3 cells were pre-treated with vehicle control (DMSO), $10 \mu \mathrm{M}$ U0126 or $10 \mu \mathrm{M} \mathrm{LY} 294002$ for $1 \mathrm{~h}$ and then treated with vehicle control (Ctrl) or $10 \mathrm{ng} / \mathrm{mL}$ AREG (AR) for $3 \mathrm{~h}$. The mRNA (A) and protein (B) levels of SPRY2 were examined by RT-qPCR and Western blot, respectively. C and D. SKOV3 (C) and OVCAR5 (D) cells were transfected with $50 \mathrm{nM}$ control siRNA (si-Ctrl) or ERK1/2 siRNAs (si-ERK1/2) for $48 \mathrm{~h}$ and then treated with vehicle control (Ctrl) or $10 \mathrm{ng} / \mathrm{mL}$ AREG (AR) for $3 \mathrm{~h}$. The protein levels of SPRY2 and ERK1/2 were examined by Western blot. The results are presented as the mean \pm SEM of at least three independent experiments. Values without a common letter are significantly different $(P<0.05)$. 
whether SPRY2 overexpression can attenuate AREGinduced cell invasion. Matrigel invasion assays showed that treatment with AREG for $48 \mathrm{~h}$ increased the invasiveness of both SKOV3 and OVCAR5 cells. Importantly, overexpression of SPRY2 did not affect basal cell invasion but did significantly attenuate the

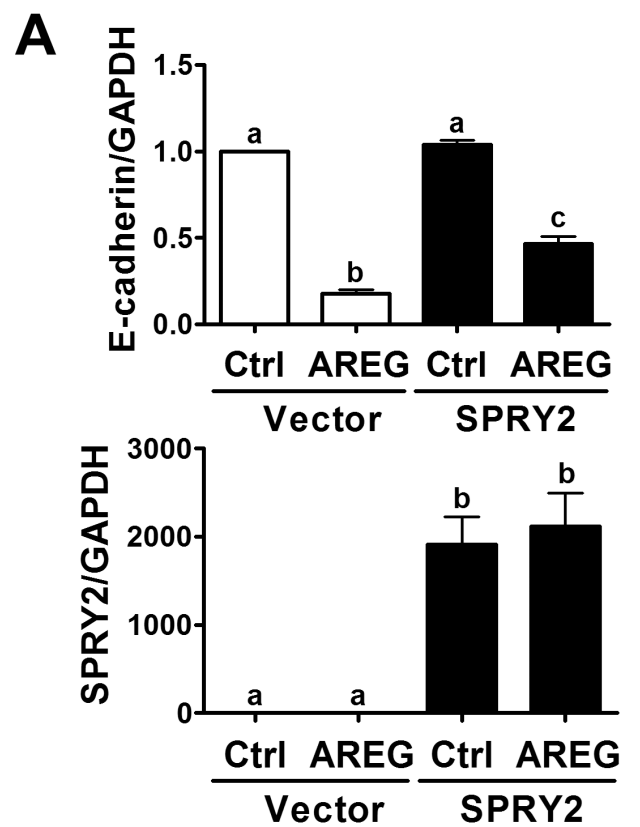

C
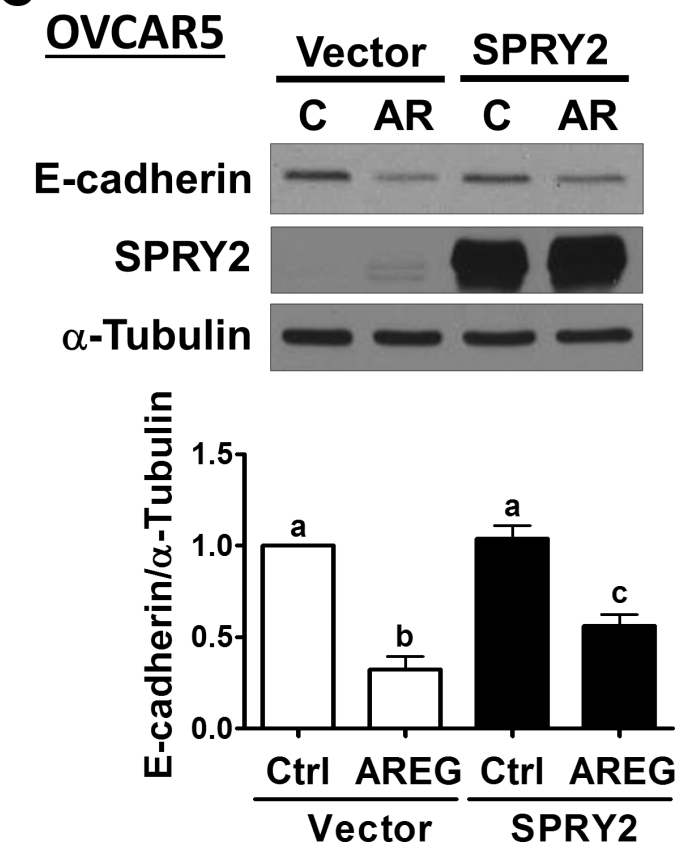

AREG-induced invasion of both cell lines (Figure 8A). To confirm that the stimulatory effect of AREG on cell invasion was not due to the effects of AREG-induced cell growth, cell proliferation after AREG treatment was examined using a trypan blue exclusion assay. As shown in Figure 8B,
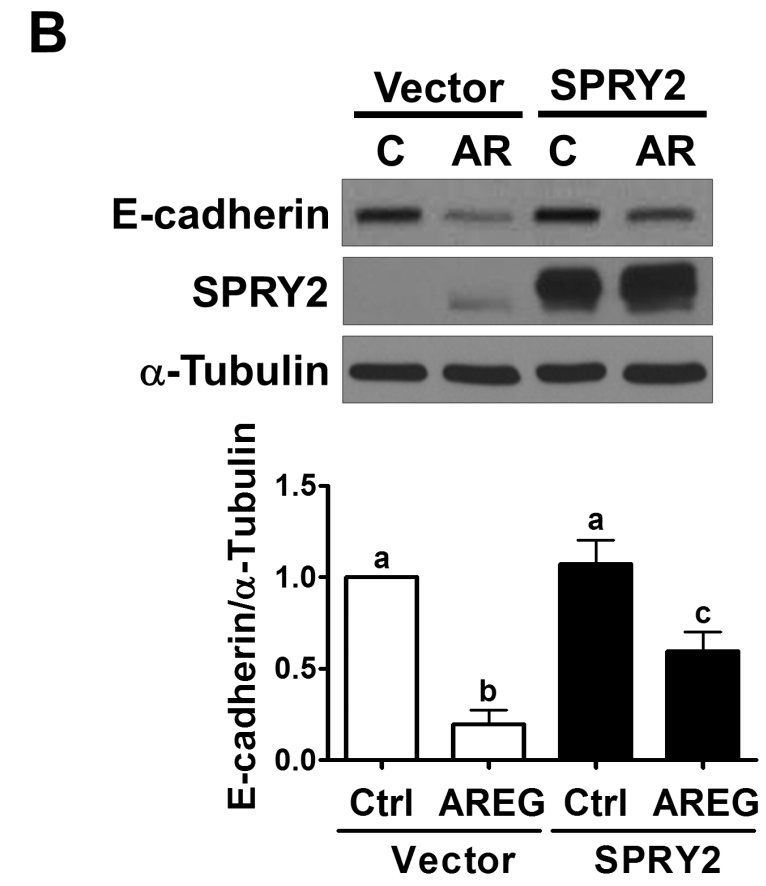

Figure 6: Overexpression of SPRY2 attenuates the AREG-induced down-regulation of E-cadherin expression. A and B. SKOV3 cells were transfected for $48 \mathrm{~h}$ with $1 \mu \mathrm{g}$ control vector (Vector) or SPRY2 overexpression vector (SPRY2) and then treated with 10 $\mathrm{ng} / \mathrm{mL}$ AREG (AR) for $3 \mathrm{~h}$. The mRNA (A) and protein (B) levels of E-cadherin and SPRY2 were examined by RT-qPCR and Western blot, respectively. C. OVCAR5 cells were transfected for $48 \mathrm{~h}$ with $1 \mu \mathrm{g}$ control vector (Vector) or SPRY2 overexpression vector (SPRY2) and then treated with $10 \mathrm{ng} / \mathrm{mL}$ AREG (AR) for $3 \mathrm{~h}$. The protein levels of E-cadherin and SPRY2 were examined by Western blot. The results are presented as the mean \pm SEM of at least three independent experiments. Values without a common letter are significantly different $(P$ $<0.05)$. 
AREG treatment only increased cell proliferation after $72 \mathrm{~h}$ in culture. Interestingly, in both SKOV3 and OVCAR5 cells, overexpression of SPRY2 attenuated AREG-stimulated cell proliferation but did not significantly affect the basal cell proliferation.

\section{Down-regulation of SPRY2 mRNA is associated with reduced overall survival and disease-free survival in patients with ovarian cancer}

To examine the relationship between SPRY2 expression and the survival of patients with ovarian cancer, we queried the Cancer Genome Atlas (TCGA) Research Network dataset. As shown in Figure 9A, 16 (3\%) of 489 cases had either up-regulation or down-regulation of SPRY2 mRNA levels. Up-regulation of SPRY2 mRNA was only detected in $4(0.8 \%)$ of 489 cases, whereas $12(2.5 \%)$ of 489 cases had down-regulation of SPRY2 mRNA. Kaplan-Meier analyses showed that up-regulation of SPRY2 mRNA was not associated with overall survival (Log-rank $P=0.173$ ) or disease-free survival (Log-rank $P=0.05$ ) (Figure 9B). Interestingly, patients with downregulation of SPRY2 mRNA had significantly poorer overall survival (Log-rank $P=0.00421$ ) and disease-free
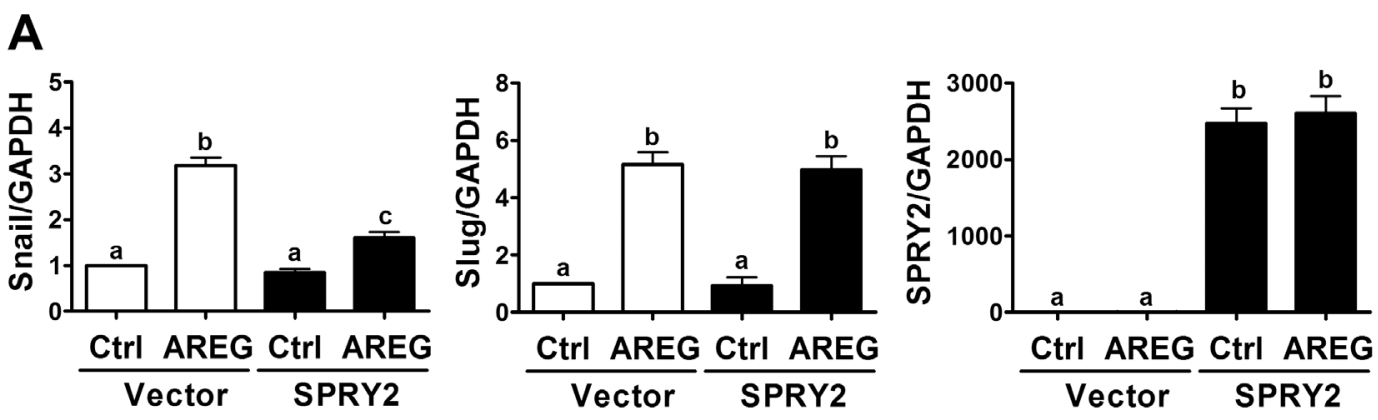

B
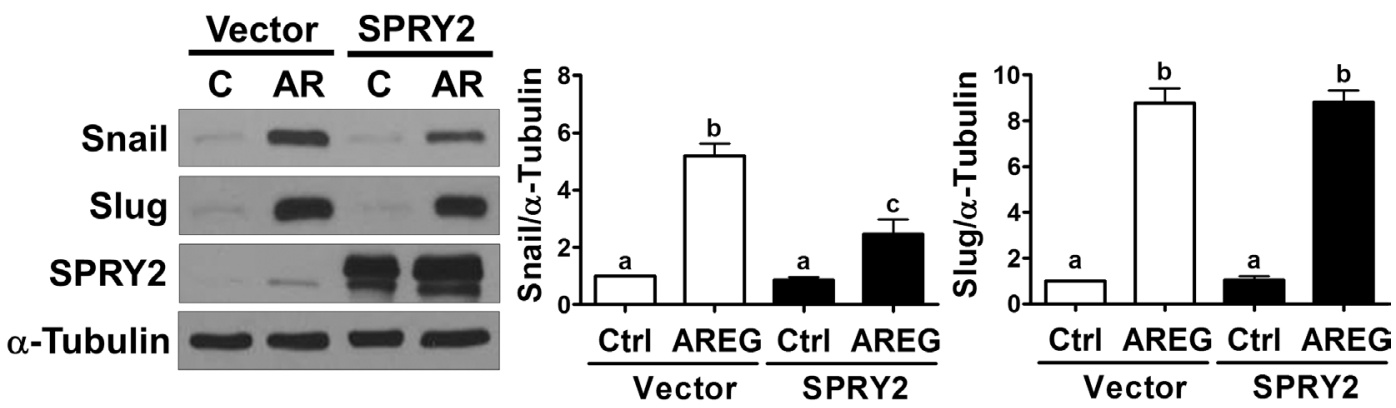

C

\section{OVCAR5}
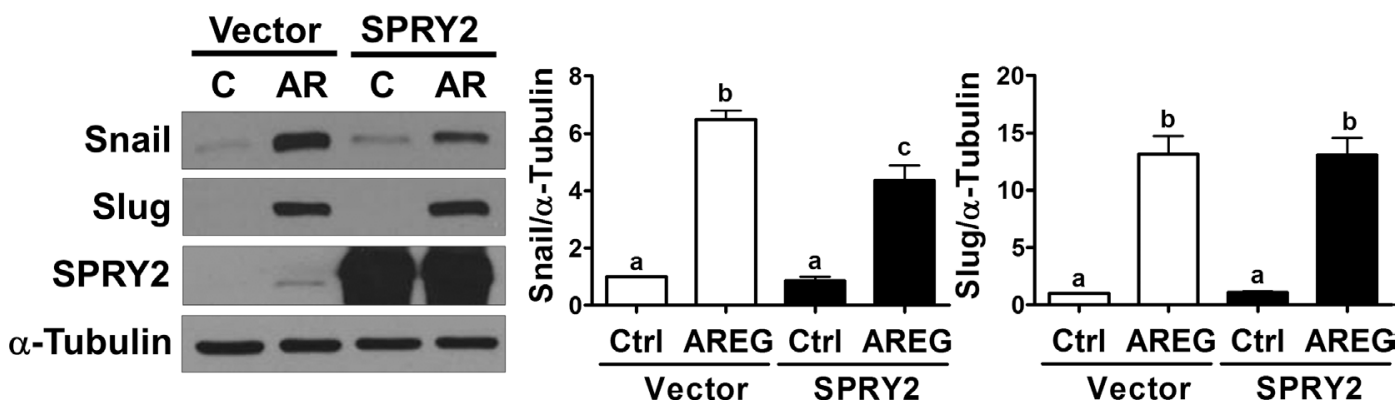

Figure 7: Overexpression of SPRY2 attenuates the AREG-induced up-regulation of Snail expression. A and B. SKOV3 cells were transfected for $48 \mathrm{~h}$ with $1 \mu \mathrm{g}$ control vector (Vector) or SPRY2 overexpression vector (SPRY2) and then treated with $10 \mathrm{ng} /$ $\mathrm{mL}$ AREG (AR) for $3 \mathrm{~h}$. The mRNA (A) and protein (B) levels of Snail, Slug and SPRY2 were examined by RT-qPCR and Western blot, respectively. C. OVCAR5 cells were transfected for $48 \mathrm{~h}$ with $1 \mu \mathrm{g}$ control vector (Vector) or SPRY2 overexpression vector (SPRY2) and then treated with $10 \mathrm{ng} / \mathrm{mL}$ AREG (AR) for $3 \mathrm{~h}$. The protein levels of Snail, Slug and SPRY2 were examined by Western blot. The results are presented as the mean $\pm \mathrm{SEM}$ of at least three independent experiments. Values without a common letter are significantly different $(P$ $<0.05)$. 
survival (Log-rank $P=0.0119$ ) (Figure 9C). These results indicate that SPRY2 acts as a tumor suppressor in human ovarian cancer.

\section{DISCUSSION}

SPRY2 expression levels are down-regulated in human ovarian cancer, and patients with low SPRY2 expression have significantly poorer survival than those with high SPRY2 expression [25-28]. In the present study, we provide new evidence that SPRY2 can antagonize the AREG-induced down-regulation of E-cadherin and invasion of human ovarian cancer cells. EGFR signaling not only regulates normal biological functions such as cell proliferation, migration, invasion and differentiation but also plays important roles in regulating tumorigenesis [33, 34]. Therefore, the down-regulation of SPRY2 in ovarian cancer decreases its ability to inhibit EGFR-mediated cellular functions, which subsequently contributes to tumor progression.

Accumulating evidence suggests that changes in the levels of local hormones and growth factors, along with their receptors and intracellular effectors, contribute to ovarian tumorigenesis $[35,36]$. Multiple cognate ligands, including EGF, AREG, TGF- $\alpha$, heparin-binding EGF (HB-EGF), epiregulin and betacellulin, can bind to and activate EGFR. However, only EGF, AREG and TGF- $\alpha$ bind EGFR exclusively; other ligands also bind other ERBB family receptors [3, 37, 38]. These EGFR ligands can be subdivided on the basis of their affinity for EGFR. EGF and TGF- $\alpha$ are considered high-affinity ligands

A

\section{SKOV3}

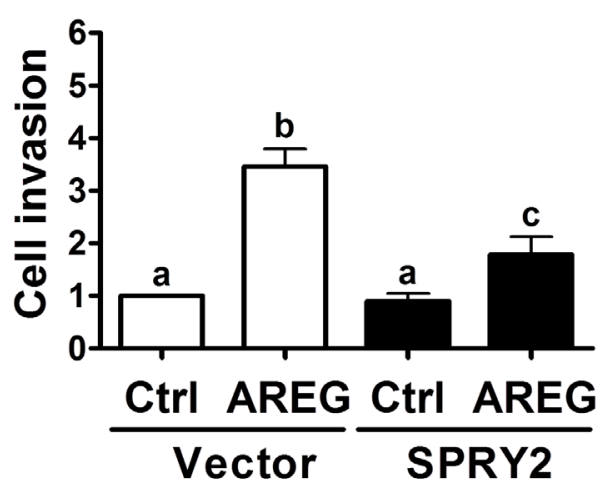

B

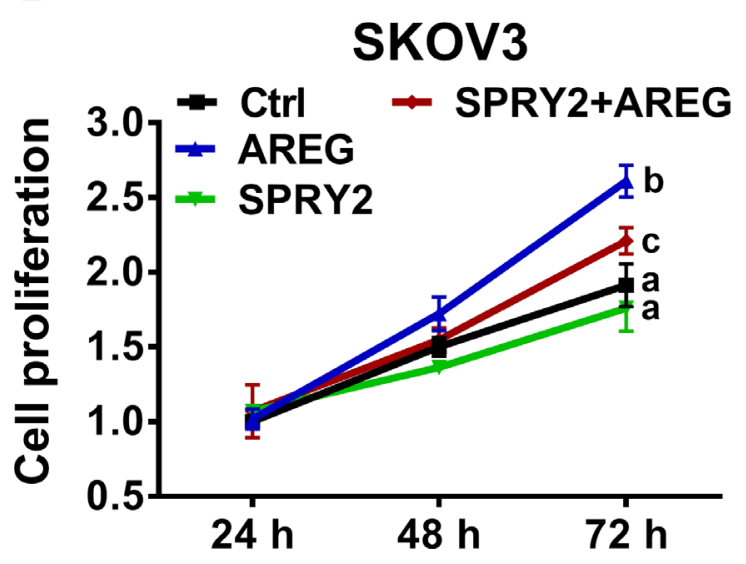

\section{OVCAR5}

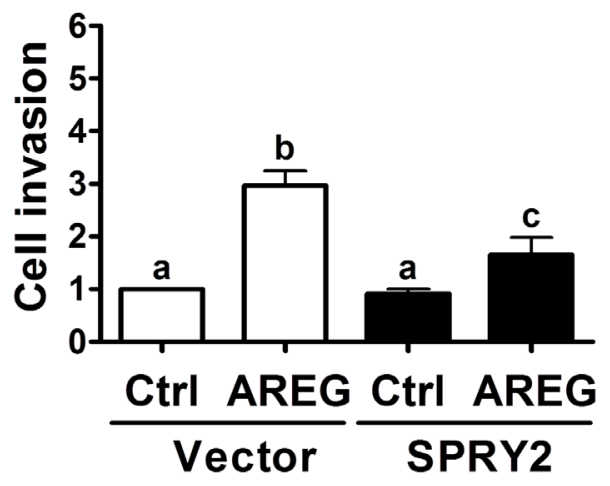

Figure 8: Overexpression of SPRY2 attenuates AREG-induced cell invasion and proliferation. A. SKOV3 (left panel) and OVCAR5 (right panel) cells were transfected with $1 \mu \mathrm{g}$ control vector (Vector) or SPRY2 overexpression vector (SPRY2) for $48 \mathrm{~h}$. After transfection, the cells were treated with $10 \mathrm{ng} / \mathrm{mL}$ AREG, and the effects of AREG on cell invasion were examined in Matrigel invasion assays. B. SKOV3 (left panel) and OVCAR5 (right panel) cells were transfected with $1 \mu \mathrm{g}$ control vector or SPRY2 overexpression vector (SPRY2) for $48 \mathrm{~h}$. After transfection, the cells were treated with $10 \mathrm{ng} / \mathrm{mL}$ AREG every $24 \mathrm{~h}$, and the number of cells was quantified using a trypan blue exclusion assay. The results are presented as the mean \pm SEM of at least three independent experiments. Values without a common letter are significantly different $(P<0.05)$. 
while AREG is considered a low-affinity ligand [39, 40]. Previous studies have shown that AREG expression levels are significantly higher than EGF and TGF- $\alpha$ levels in ovarian cancer cells, tumor tissues and peritoneal and ascites fluid from patients with ovarian cancer [7, 41-43]. In addition, the current study and our previous studies show that AREG can stimulate ovarian cancer cell invasion by down-regulating E-cadherin expression [13, 14, 20]. Moreover, AREG has been reported to regulate ovarian cancer progression in an autocrine/paracrine manner [13, 44]. Overall, these studies indicate that AREG is the dominant EGFR ligand in ovarian cancer cells and plays important roles in promoting cancer development and progression. Indeed, a recent study demonstrates that

A

Altered in $16(3 \%)$ of 489 Ovarian Serous Cystadenocarcinoma SPRY2 $3 \%$ Genetic Alteration mRNA Upregulation mRNA Downregulation
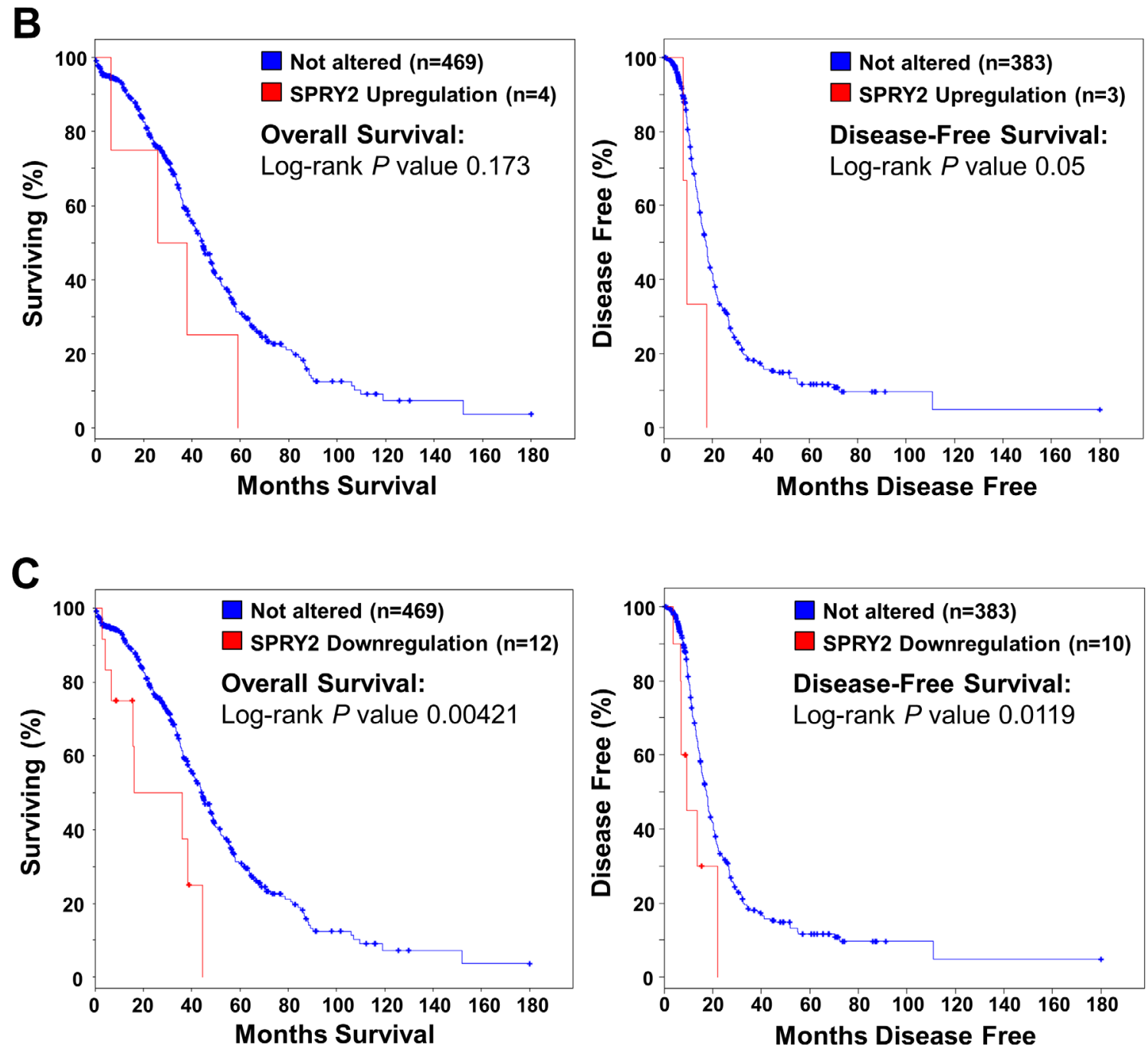

Figure 9: Down-regulation of SPRY2 mRNA is associated with reduced overall and disease-free survival in patients with high-grade serous ovarian carcinoma. The cBioPortal for Cancer Genomics was used to query high-grade serous ovarian carcinomas from The Cancer Genome Atlas $(n=489)$ for patients with altered SPRY2 mRNA levels. A. OncoPrint results showing cases with altered SPRY2 mRNA levels across all 489 high-grade serous ovarian carcinomas. B. Overall (left panel) and disease-free (right panel) survival differences between samples without and with up-regulated SPRY2 mRNA were displayed as Kaplan-Meier survival curves with the associated $P$ value (Log-rank test). C. Overall (left panel) and disease-free (right panel) survival differences between samples without and with down-regulated SPRY2 mRNA were displayed as Kaplan-Meier survival curves with the associated $P$ value (Log-rank test). 
shRNA-mediated AREG depletion or treatment with an anti-AREG monoclonal antibody inhibits the growth of human ovarian cancer cells [7]. Interestingly, cisplatin treatment increases AREG promoter activity but not EGF or TGF- $\alpha$ promoter activity, suggesting a possible role of AREG in regulating chemoresistance in ovarian cancer [7]. Taken together, these results suggest that targeting AREG is a potential new clinical approach that could lower the overall mortality and morbidity of human ovarian cancer.

It is interesting to note that despite the fact that multiple ligands can bind to and activate EGFR, they are capable of inducing different biological effects, even within the same cell [45]. For example, AREG, but not TGF- $\alpha$, induces a morphological change and E-cadherin redistribution in MDCK cells [46]. In addition, AREG exhibits greater effect than EGF on cell motility and invasiveness of human mammary epithelial cells [5]. We have shown that treatment with EGF up-regulates SPRY2 expression, and overexpression of SPRY2 attenuates EGF-induced E-cadherin down-regulation and cell invasion in human ovarian cancer cells [25]. Given the evidence that AREG plays more important roles than EGF in the regulation of ovarian cancer progression, it is interesting and important to examine whether SPRY2 can be regulated by AREG and whether SPRY2 also affects the biological functions of AREG. The data shown in the present study demonstrated that overexpression of SPRY2 attenuated AREG-induced down-regulation of E-cadherin and invasion of human ovarian cancer cells. These results indicate that AREG and EGF induce similar biological functions in human ovarian cancer cells. In addition, in response to the AREG and EGF treatments, SPRY2 inhibits both EGFR ligands-induced E-cadherin downregulation and cell invasion.

Since the discovery that SPRY proteins inhibit FGF receptor signaling during tracheal development in Drosophila, increasing evidence has characterized the critical role of SPRY proteins in regulating receptor tyrosine kinase-mediated MAPK/ERK1/2 signaling pathway [47]. Given their critical role as modulators of MAPK/ERK1/2 signaling, the SPRY proteins are expected to be deregulated in cancer. Thus far, aberrant expression of SPRY proteins has been identified in different types of human cancer [24]. Interestingly, in a context- and/or tissue-dependent manner, SPRY2 has been shown to act as a tumor suppressor [48-53] or promoter [54-57]. A recent study shows that SPRY2 is down-regulated in human ovarian cancer and that SPRY2 expression levels are negatively correlated with cell proliferation. Importantly, patients with lower tumor SPRY2 expression have significantly poorer overall survival and disease-free survival than those with high SPRY2 expression [28]. These results are consistent with our analyses of the TCGA dataset in the present study. In addition, we showed that overexpression of SPRY2 attenuated AREG-induced ovarian cancer cell invasion. These results indicate that SPRY2 may act as a tumor suppressor in human ovarian cancer and could be used as a prognostic biomarker. Although it is not presently possible to affect SPRY2 function with small molecules, efforts to increase the specificity and efficiency of viral vectors or non-viral vectors to modulate gene expression are in ongoing development $[58,59]$. Therefore, through the more thorough dissection of the targets or signaling pathways that are regulated by SPRY2 could lead to the development of alternative therapeutic approaches for human ovarian cancer.

In the mouse, SPRY1, SPRY2 and SPRY4 expression can be detected in various embryonic tissues, whereas SPRY3 is only expressed in the adult brain and testis [22, 60]. In ovarian cancer, SPRY4 expression levels are also down-regulated, while the changes in SPRY1 expression remain controversial [25, 27, 28, 61]. Our recent study demonstrates that SPRY4 expression is involved in the AREG-induced down-regulation of E-cadherin and invasion of human ovarian cancer cells [20]. However, in the present study, we showed that SPRY2 antagonized the AREG-induced down-regulation of E-cadherin and cell invasion. These results indicate that SPRY2 and SPRY4 have opposing effects on the regulation of EGFR-mediated E-cadherin down-regulation and cell invasion in human ovarian cancer. Although SPRY4 down-regulation is detected in ovarian cancer, the expression levels of SPRY4 do not significantly correlate with overall survival or disease-free survival [28]. These results suggest that SPRY2 plays a more important role than SPRY4 in regulating human ovarian cancer progression. Future studies will be needed to investigate the molecular mechanisms underlying the different roles of SPRY2 and SPRY4 in the regulation of EGFR-mediated cellular function in human ovarian cancer.

We have shown that AREG up-regulates Snail and Slug expression, and both Snail and Slug are required for the AREG-induced down-regulation of E-cadherin in human ovarian cancer cells $[13,14]$. The results of the present study showed that basal Snail, Slug and E-cadherin expression was not affected by SPRY2 overexpression in two human ovarian cancer cell lines, SKOV3 and OVCAR5, while the AREG-induced up-regulation of Snail, down-regulation of E-cadherin and increase in cell invasion were attenuated by SPRY2 overexpression. Interestingly, in contrast to our results, SPRY2 can suppress both basal and 1 1,25-dihydroxyvitamin D3induced E-cadherin expression, and SPRY2 expression levels are negatively correlated with E-cadherin expression levels in human colon cancer cells [54]. These results suggest cancer type-specific roles of SPRY2 in cancer development and progression.

In summary, the present study demonstrates that AREG expression levels are negatively correlated with patient survival. Treatment with AREG up-regulates 
SPRY2 expression in two human ovarian cancer cell lines. The stimulatory effect of AREG on SPRY2 expression is mediating by the ERK1/2 signaling pathway. In addition, our results show that overexpression of SPRY2 attenuates the AREG-induced up-regulation of Snail, downregulation of E-cadherin, cell invasion and proliferation. Moreover, down-regulation of SPRY2 expression is associated with poor survival. These results suggest a tumor suppressor role for SPRY2 in human ovarian cancer and provide a possible target for the development of novel therapeutic strategies.

\section{MATERIALS AND METHODS}

\section{Cell culture}

The SKOV3 human ovarian cancer cell line was obtained from American Type Culture Collection (Manassas, VA). The OVCAR5 human ovarian cancer line was kindly provided by Dr. T.C. Hamilton (Fox Chase Cancer Center, Philadelphia, PA). Cells were grown in a 1:1 (v/v) mixture of M199/MCDB105 medium (Sigma, Oakville, ON) supplemented with $10 \%$ fetal bovine serum (FBS; HyClone Laboratories Inc., Logan, UT). The cultures were maintained at $37^{\circ} \mathrm{C}$ in a humidified $5 \% \mathrm{CO}_{2}$ atmosphere.

\section{Antibodies and reagents}

The polyclonal anti-Sprouty2 antibody (\#S1444) was obtained from Sigma. The monoclonal anti-E-cadherin antibody (\#610181) was obtained from BD Biosciences (Mississauga, ON). The polyclonal anti-EGFR (\#sc-03) and monoclonal anti- $\alpha$-tubulin (\#sc-23948) antibodies were obtained from Santa Cruz Biotechnology (Santa Cruz, CA). The polyclonal anti-ERK1/2 (\#9102), anti-Slug (\#9585) and monoclonal anti-Snail (\#3895) antibodies were obtained from Cell Signaling Technology (Danvers, MA). Horseradish peroxidase-conjugated goat anti-mouse $\mathrm{IgG}$ and goat anti-rabbit IgG were obtained from Bio-Rad Laboratories (Hercules, CA). AG1478 and LY294002 were obtained from Sigma. U0126 was obtained from Calbiochem (San Diego, CA). Recombinant human AREG was purchased from R\&D Systems (Minneapolis, MN).

\section{Small interfering RNA (siRNA) transfection and overexpression}

For endogenous EGFR or ERK1/2 knockdown, the cells were transfected with $50 \mathrm{nM}$ ON-TARGETplus SMARTpool specific siRNA (Dharmacon Research, Inc., Lafayette, $\mathrm{CO}$ ) using Lipofectamine RNAiMAX (Invitrogen, Burlington, ON). Non-targeting siCONTROL siRNA (Dharmacon) was used as a transfection control. To overexpress human SPRY2, the pXJ40-FLAG-SPRY2 vector and empty pXJ40-FLAG vector (gifts from Dr.
Graeme R. Guy, Institute of Molecular and Cell Biology, Singapore) [62] were transfected using Lipofectamine 3000 (Invitrogen).

\section{Real-time quantitative PCR (RT-qPCR)}

Total RNA was extracted using TRIzol reagent (Invitrogen) according to the manufacturer's instructions. Reverse transcription was performed with $3 \mu \mathrm{g}$ RNA, random primers and M-MLV reverse transcriptase (Promega, Madison, WI). The primers used for SYBR Green RT-qPCR were as follows: SPRY2, forward 5'-CCC CTC TGT CCA GAT CCA TA- ${ }^{\prime}$ and reverse 5 '-CCC AAA TCT TCC TTG CTC AG-3'; EGFR, forward 5'-GGT GCA GGA GAG GAG AAC TGC-3' and reverse 5'-GGT GGC ACC AAA GCT GTA TT-3'; E-cadherin, forward 5'-ACA GCC CCG CCT TAT GAT T-3' and reverse 5'TCG GAA CCG CTT CCT TCA-3'; Snail, forward 5'-CCC CAA TCG GAA GCC TAA CT-3' and reverse 5'- GCT GGA AGG TAA ACT CTG GAT TAG A-3'; Slug, forward 5'-TTC GGA CCC ACA CAT TAC CT-3' and reverse 5'-GCA GTG AGG GCA AGA AAA AG3'; and GAPDH, forward 5'-GAG TCA ACG GAT TTG GTC GT-3' and reverse 5'-GAC AAG CTT CCC GTT CTC AG-3'. RT-qPCR was performed using an Applied Biosystems 7300 Real-Time PCR System (Perkin-Elmer) equipped with a 96-well optical reaction plate. All RTqPCR data are presented as the mean of at least three independent experiments conducted in triplicate. The relative quantification of mRNA levels was performed by the comparative $\mathrm{Ct}$ method using GAPDH as the reference gene and the formula $2^{-\Delta \Delta \mathrm{Ct}}$.

\section{Western blot}

Cells were lysed in lysis buffer (Cell Signaling Technology), and protein concentration was determined using a DC protein assay kit with BSA as the standard (Bio-Rad Laboratories). Equal amounts of protein were separated by SDS-polyacrylamide gel electrophoresis and transferred to PVDF membranes. After blocking in Trisbuffered saline (TBS) containing 5\% non-fat dry milk for $1 \mathrm{~h}$, the membranes were incubated overnight at $4{ }^{\circ} \mathrm{C}$ with primary antibodies, followed by incubation with the HRP-conjugated secondary antibody. Immunoreactive bands were detected with an enhanced chemiluminescent substrate (Pierce, Rockford, IL).

\section{Invasion assay}

Invasion assays were performed in Boyden chambers with minor modifications [63]. Cell culture inserts (24-well, $8-\mu \mathrm{m}$ pore size; BD Biosciences, Mississauga, ON) pre-coated with growth factor-reduced Matrigel ( $40 \mu \mathrm{L}, 1 \mathrm{mg} / \mathrm{mL}$; BD Biosciences) were used for invasion assays. Cell culture inserts were seeded with $1 \times 10^{5}$ cells in $250 \mu \mathrm{L}$ of medium with $0.1 \%$ FBS. Medium 
with $10 \%$ FBS $(750 \mu \mathrm{L})$ was added to the lower chamber and served as a chemotactic agent. After $48 \mathrm{~h}$ incubation, non-invading cells were removed from the upper side of the membrane, and cells on the lower side were fixed with cold methanol and air dried. The cells were stained with crystal violet (Sigma) and counted. Each individual experiment was performed with triplicate inserts, and five microscopic fields were counted per insert.

\section{Statistical analysis}

The results are presented as the mean \pm SEM of at least three independent experiments. The results were analyzed by one-way ANOVA and Tukey's multiple comparison test using PRISM software. Significant differences were defined by values of $P<0.05$.

\section{ACKNOWLEDGMENTS}

This work was supported by an operating grant from the Canadian Institutes of Health Research to P.C.K.L (\#143317).

\section{DISCLOSURE STATEMENT}

The authors have nothing to disclose

\section{GRANT SUPPORT}

This work was supported by an operating grant from the Canadian Institutes of Health Research to P.C.K.L (\#143317).

\section{REFERENCES}

1. Siwak DR, Carey M, Hennessy BT, Nguyen CT, McGahren Murray MJ, Nolden L, Mills GB. Targeting the epidermal growth factor receptor in epithelial ovarian cancer: current knowledge and future challenges. Journal of oncology. 2010; 2010:568938.

2. Gui T, Shen K. The epidermal growth factor receptor as a therapeutic target in epithelial ovarian cancer. Cancer epidemiology. 2012; 36:490-496.

3. Yarden Y, Sliwkowski MX. Untangling the ErbB signalling network. Nature reviews Molecular cell biology. 2001; 2:127-137.

4. Normanno N, De Luca A, Bianco C, Strizzi L, Mancino M, Maiello MR, Carotenuto A, De Feo G, Caponigro F, Salomon DS. Epidermal growth factor receptor (EGFR) signaling in cancer. Gene. 2006; 366:2-16.

5. Willmarth NE, Ethier SP. Autocrine and juxtacrine effects of amphiregulin on the proliferative, invasive, and migratory properties of normal and neoplastic human mammary epithelial cells. The Journal of biological chemistry. 2006; 281:37728-37737.
6. Wilson KJ, Mill C, Lambert S, Buchman J, Wilson TR, Hernandez-Gordillo V, Gallo RM, Ades LM, Settleman J, Riese DJ, 2nd. EGFR ligands exhibit functional differences in models of paracrine and autocrine signaling. Growth factors. 2012; 30:107-116.

7. Carvalho S, Lindzen M, Lauriola M, Shirazi N, Sinha S, Abdul-Hai A, Levanon K, Korach J, Barshack I, Cohen Y, Onn A, Mills G, Yarden Y. An antibody to amphiregulin, an abundant growth factor in patients' fluids, inhibits ovarian tumors. Oncogene. 2016; 35:438-447.

8. Pecina-Slaus N. Tumor suppressor gene E-cadherin and its role in normal and malignant cells. Cancer Cell Int. 2003; $3: 17$.

9. Thiery JP. Epithelial-mesenchymal transitions in tumour progression. Nat Rev Cancer. 2002; 2:442-454.

10. Veatch AL, Carson LF, Ramakrishnan S. Differential expression of the cell-cell adhesion molecule E-cadherin in ascites and solid human ovarian tumor cells. Int J Cancer. 1994; 58:393-399.

11. Darai E, Scoazec JY, Walker-Combrouze F, Mlika-Cabanne N, Feldmann G, Madelenat P, Potet F. Expression of cadherins in benign, borderline, and malignant ovarian epithelial tumors: a clinicopathologic study of 60 cases. Hum Pathol. 1997; 28:922-928.

12. Zhao J, Klausen C, Qiu X, Cheng JC, Chang HM, Leung PC. Betacellulin induces Slug-mediated down-regulation of E-cadherin and cell migration in ovarian cancer cells. Oncotarget. 2016; 7:28881-28890. doi: 10.18632/ oncotarget.7591.

13. So WK, Fan Q, Lau MT, Qiu X, Cheng JC, Leung PC. Amphiregulin induces human ovarian cancer cell invasion by down-regulating E-cadherin expression. FEBS letters. 2014; 588:3998-4007.

14. Qiu X, Cheng JC, Klausen C, Fan Q, Chang HM, So WK, Leung PC. Transforming growth factor-alpha induces human ovarian cancer cell invasion by down-regulating E-cadherin in a Snail-independent manner. Biochemical and biophysical research communications. 2015; 461:128-135.

15. Qiu X, Cheng JC, Chang HM, Leung PC. COX2 and PGE2 mediate EGF-induced E-cadherin-independent human ovarian cancer cell invasion. Endocr Relat Cancer. 2014; 21:533-543.

16. Cheng JC, Qiu X, Chang HM, Leung PC. HER2 mediates epidermal growth factor-induced down-regulation of E-cadherin in human ovarian cancer cells. Biochemical and biophysical research communications. 2013; 434:81-86.

17. Cheng JC, Klausen C, Leung PC. Hypoxia-inducible factor 1 alpha mediates epidermal growth factor-induced down-regulation of E-cadherin expression and cell invasion in human ovarian cancer cells. Cancer Lett. 2013; 329:197-206.

18. Cheng JC, Klausen C, Leung PC. Hydrogen peroxide mediates EGF-induced down-regulation of E-cadherin expression via p38 MAPK and snail in human ovarian cancer cells. Molecular endocrinology. 2010; 24:1569-1580. 
19. Cheng JC, Chang HM, Leung PC. Egr-1 mediates epidermal growth factor-induced downregulation of E-cadherin expression via Slug in human ovarian cancer cells. Oncogene. 2013; 32:1041-1049.

20. So WK, Cheng JC, Liu Y, Xu C, Zhao J, Chang VT, Leung PC. Sprouty4 mediates amphiregulin-induced downregulation of E-cadherin and cell invasion in human ovarian cancer cells. Tumour biology. 2016; 37:9197-9207.

21. Hacohen N, Kramer S, Sutherland D, Hiromi Y, Krasnow MA. Sprouty encodes a novel antagonist of FGF signaling that patterns apical branching of the Drosophila airways. Cell. 1998; 92:253-263.

22. Minowada G, Jarvis LA, Chi CL, Neubuser A, Sun X, Hacohen N, Krasnow MA, Martin GR. Vertebrate Sprouty genes are induced by FGF signaling and can cause chondrodysplasia when overexpressed. Development. 1999; 126:4465-4475.

23. Guy GR, Jackson RA, Yusoff P, Chow SY. Sprouty proteins: modified modulators, matchmakers or missing links? The Journal of endocrinology. 2009; 203:191-202.

24. Masoumi-Moghaddam S, Amini A, Morris DL. The developing story of Sprouty and cancer. Cancer metastasis reviews. 2014; 33:695-720.

25. So WK, Cheng JC, Fan Q, Wong AS, Huntsman DG, Gilks CB, Leung PC. Loss of Sprouty2 in human highgrade serous ovarian carcinomas promotes EGF-induced E-cadherin down-regulation and cell invasion. FEBS letters. 2015; 589:302-309.

26. Masoumi-Moghaddam S, Amini A, Wei AQ, Robertson G, Morris DL. Sprouty2 protein in prediction of post-treatment ascites in epithelial ovarian cancer treated with adjuvant carbotaxol chemotherapy. American journal of cancer research. 2015; 5:2498-2507.

27. Moghaddam SM, Amini A, Wei AQ, Pourgholami MH, Morris DL. Initial report on differential expression of sprouty proteins 1 and 2 in human epithelial ovarian cancer cell lines. Journal of oncology. 2012; 2012:373826.

28. Masoumi-Moghaddam S, Amini A, Wei AQ, Robertson G, Morris DL. Sprouty 2 protein, but not Sprouty 4, is an independent prognostic biomarker for human epithelial ovarian cancer. International journal of cancer. 2015; 137:560-570.

29. Cancer Genome Atlas Research N. Integrated genomic analyses of ovarian carcinoma. Nature. 2011; 474:609-615.

30. Gao J, Aksoy BA, Dogrusoz U, Dresdner G, Gross B, Sumer SO, Sun Y, Jacobsen A, Sinha R, Larsson E, Cerami E, Sander C, Schultz N. Integrative analysis of complex cancer genomics and clinical profiles using the cBioPortal. Science signaling. 2013; 6:pl1.

31. Inoue Y, Miyamoto S, Fukami T, Shirota K, Yotsumoto F, Kawarabayashi T. Amphiregulin is much more abundantly expressed than transforming growth factor-alpha and epidermal growth factor in human follicular fluid obtained from patients undergoing in vitro fertilization-embryo transfer. Fertil Steril. 2009; 91:1035-1041.

32. Peinado H, Olmeda D, Cano A. Snail, Zeb and bHLH factors in tumour progression: an alliance against the epithelial phenotype? Nat Rev Cancer. 2007; 7:415-428.

33. Hynes NE, Lane HA. ERBB receptors and cancer: the complexity of targeted inhibitors. Nat Rev Cancer. 2005; 5:341-354.

34. Hynes NE, MacDonald G. ErbB receptors and signaling pathways in cancer. Curr Opin Cell Biol. 2009; 21:177-184.

35. Vaughan S, Coward JI, Bast RC, Jr., Berchuck A, Berek JS, Brenton JD, Coukos G, Crum CC, Drapkin R, Etemadmoghadam D, Friedlander M, Gabra H, Kaye SB, Lord CJ, Lengyel E, Levine DA, et al. Rethinking ovarian cancer: recommendations for improving outcomes. Nature reviews Cancer. 2011; 11:719-725.

36. Bowtell DD, Bohm S, Ahmed AA, Aspuria PJ, Bast RC, Jr., Beral V, Berek JS, Birrer MJ, Blagden S, Bookman MA, Brenton JD, Chiappinelli KB, Martins FC, Coukos G, Drapkin R, Edmondson R, et al. Rethinking ovarian cancer II: reducing mortality from high-grade serous ovarian cancer. Nature reviews Cancer. 2015; 15:668-679.

37. Harris RC, Chung E, Coffey RJ. EGF receptor ligands. Experimental cell research. 2003; 284:2-13.

38. Citri A, Yarden Y. EGF-ERBB signalling: towards the systems level. Nature reviews Molecular cell biology. 2006; 7:505-516.

39. Kochupurakkal BS, Harari D, Di-Segni A, Maik-Rachline G, Lyass L, Gur G, Kerber G, Citri A, Lavi S, Eilam R, Chalifa-Caspi V, Eshhar Z, Pikarsky E, Pinkas-Kramarski R, Bacus SS, Yarden Y. Epigen, the last ligand of ErbB receptors, reveals intricate relationships between affinity and mitogenicity. The Journal of biological chemistry. 2005; 280:8503-8512.

40. Jones JT, Akita RW, Sliwkowski MX. Binding specificities and affinities of egf domains for ErbB receptors. FEBS letters. 1999; 447:227-231.

41. Yotsumoto F, Yagi H, Suzuki SO, Oki E, Tsujioka H, Hachisuga T, Sonoda K, Kawarabayashi T, Mekada E, Miyamoto S. Validation of HB-EGF and amphiregulin as targets for human cancer therapy. Biochem Biophys Res Commun. 2008; 365:555-561.

42. Tanaka Y, Miyamoto S, Suzuki SO, Oki E, Yagi H, Sonoda K, Yamazaki A, Mizushima H, Maehara Y, Mekada E, Nakano H. Clinical significance of heparin-binding epidermal growth factor-like growth factor and a disintegrin and metalloprotease 17 expression in human ovarian cancer. Clin Cancer Res. 2005; 11:4783-4792.

43. Yagi H, Miyamoto S, Tanaka Y, Sonoda K, Kobayashi H, Kishikawa T, Iwamoto R, Mekada E, Nakano H. Clinical significance of heparin-binding epidermal growth factorlike growth factor in peritoneal fluid of ovarian cancer. Br J Cancer. 2005; 92:1737-1745. 
44. Panupinthu N, Yu S, Zhang D, Zhang F, Gagea M, Lu Y, Grandis JR, Dunn SE, Lee HY, Mills GB. Self-reinforcing loop of amphiregulin and Y-box binding protein-1 contributes to poor outcomes in ovarian cancer. Oncogene. $2014 ; 33: 2846-2856$.

45. Wilson KJ, Gilmore JL, Foley J, Lemmon MA, Riese DJ, 2nd. Functional selectivity of EGF family peptide growth factors: implications for cancer. Pharmacology \& therapeutics. 2009; 122:1-8.

46. Chung E, Graves-Deal R, Franklin JL, Coffey RJ. Differential effects of amphiregulin and TGF-alpha on the morphology of MDCK cells. Experimental cell research. 2005; 309:149-160.

47. Cabrita MA, Christofori G. Sprouty proteins, masterminds of receptor tyrosine kinase signaling. Angiogenesis. 2008; 11:53-62.

48. Schutzman JL, Martin GR. Sprouty genes function in suppression of prostate tumorigenesis. Proceedings of the National Academy of Sciences of the United States of America. 2012; 109:20023-20028.

49. Feng YH, Wu CL, Tsao CJ, Chang JG, Lu PJ, Yeh KT, Uen YH, Lee JC, Shiau AL. Deregulated expression of sprouty2 and microRNA-21 in human colon cancer: Correlation with the clinical stage of the disease. Cancer biology \& therapy. 2011; 11:111-121.

50. McKie AB, Douglas DA, Olijslagers S, Graham J, Omar MM, Heer R, Gnanapragasam VJ, Robson CN, Leung HY. Epigenetic inactivation of the human sprouty2 (hSPRY2) homologue in prostate cancer. Oncogene. 2005; 24:2166-2174.

51. Lee SA, Ho C, Roy R, Kosinski C, Patil MA, Tward AD, Fridlyand J, Chen X. Integration of genomic analysis and in vivo transfection to identify sprouty 2 as a candidate tumor suppressor in liver cancer. Hepatology. 2008; 47:1200-1210.

52. Sutterluty H, Mayer CE, Setinek U, Attems J, Ovtcharov S, Mikula M, Mikulits W, Micksche M, Berger W. Downregulation of Sprouty2 in non-small cell lung cancer contributes to tumor malignancy via extracellular signalregulated kinase pathway-dependent and -independent mechanisms. Molecular cancer research: MCR. 2007; 5:509-520.

53. Velasco A, Pallares J, Santacana M, Gatius S, Fernandez M, Domingo M, Valls J, Yeramian A, Encinas M, Dolcet X,
Matias-Guiu X. Promoter hypermethylation and expression of sprouty 2 in endometrial carcinoma. Human pathology. 2011; 42:185-193.

54. Barbachano A, Ordonez-Moran P, Garcia JM, Sanchez A, Pereira F, Larriba MJ, Martinez N, Hernandez J, Landolfi S, Bonilla F, Palmer HG, Rojas JM, Munoz A. SPROUTY-2 and E-cadherin regulate reciprocally and dictate colon cancer cell tumourigenicity. Oncogene. 2010; 29:4800-4813.

55. Holgren C, Dougherty U, Edwin F, Cerasi D, Taylor I, Fichera A, Joseph L, Bissonnette M, Khare S. Sprouty-2 controls c-Met expression and metastatic potential of colon cancer cells: sprouty/c-Met upregulation in human colonic adenocarcinomas. Oncogene. 2010; 29:5241-5253.

56. Lito P, Mets BD, Appledorn DM, Maher VM, McCormick JJ. Sprouty 2 regulates DNA damage-induced apoptosis in Ras-transformed human fibroblasts. The Journal of biological chemistry. 2009; 284:848-854.

57. Lito P, Mets BD, Kleff S, O'Reilly S, Maher VM, McCormick JJ. Evidence that sprouty 2 is necessary for sarcoma formation by H-Ras oncogene-transformed human fibroblasts. The Journal of biological chemistry. 2008; 283:2002-2009.

58. Zhao Y, Huang L. Lipid nanoparticles for gene delivery. Advances in genetics. 2014; 88:13-36.

59. Giacca M, Zacchigna S. Virus-mediated gene delivery for human gene therapy. Journal of controlled release: official journal of the Controlled Release Society. 2012; 161:377-388.

60. Zhang S, Lin Y, Itaranta P, Yagi A, Vainio S. Expression of Sprouty genes 1, 2 and 4 during mouse organogenesis. Mech Dev. 2001; 109:367-370.

61. Masoumi-Moghaddam S, Amini A, Wei AQ, Robertson G, Morris DL. Sprouty 1 predicts prognosis in human epithelial ovarian cancer. American journal of cancer research. 2015; 5:1531-1541.

62. Wong ES, Lim J, Low BC, Chen Q, Guy GR. Evidence for direct interaction between Sprouty and Cbl. J Biol Chem. 2001; 276:5866-5875.

63. Woo MM, Salamanca CM, Minor A, Auersperg N. An improved assay to quantitate the invasiveness of cells in modified Boyden chambers. In Vitro Cell Dev Biol Anim. 2007; 43:7-9. 